\title{
Saussure $\mathrm{e} o$ aspecto fônico da língua Saussure and the phonic aspect of language
}

\section{Luiza Milano}

(Universidade Federal do Rio Grande do Sul - Instituto de Letras/Departamento de Letras Clássicas e Vernáculas - Porto Alegre - Rio Grande do Sul - Brasil)

\section{RESUMO}

O presente artigo tem como objetivo realizar um percurso de leitura acerca da importância do aspecto fônico da língua no legado do mestre genebrino Ferdinand de Saussure. Partindo das noções de concreto e abstrato presentes no clássico livro Curso de Linguística Geral (CLG), são analisados os conceitos de fonema, fonética e fonologia presentes na obra. A abordagem da materialidade fônica no CLG é contrastada com duas outras importantes fontes manuscritas do autor, os Escritos de Linguística Geral e o manuscrito harvardiano Phonétique.

Palavras-chave: Fonema; Fonética; Fonologia; Saussure, Ferdinand de.

1. Professora do Programa de Pós-Graduação em Letras da Universidade Federal do Rio Grande do Sul - UFRGS. 


\section{ABSTRACT}

The present paper aims to carry out a reading path concerning the importance of the phonic aspect of language in the legacy of Genevan master Ferdinand de Saussure. Starting from the concrete and abstract notions present in the classic book Course in General Linguistics (CLG), the concepts of phoneme, phonetics and phonology are analyzed in the work. The approach of phonic materiality in CLG is in contrast with two other important manuscript sources of the author: Writings in General Linguistics and Harvard's manuscript Phonétique.

Key-words: Phoneme; Phonetics; Phonology; Saussure, Ferdinand de.

\section{Introdução}

A reflexão acerca do aspecto fônico da língua a partir do legado de Ferdinand de Saussure, embora não muito difundida, não é nova. Aqueles que começaram a leitura do clássico livro Curso de Linguística Geral pelo excelente prefácio à edição brasileira de Isaac Nicolau Salum (Saussure 1974: XVI), foram alertados de que esse foi um dos principais temas abordados por Saussure em seu primeiro Curso de Linguística Geral, ministrado de 16 de janeiro a 3 de julho de 1907, na Universidade de Genebra.

De uma maneira geral, quando se inicia os estudos sobre o fônico em Saussure, costuma-se apontar dois caminhos relevantes. O primeiro diz respeito ao fato de que Saussure, já na primeira edição das aulas de seu Curso de Línguística Geral, conforme apontamos acima, ter dado, ao estudo dos sons das línguas, lugar de destaque. Ainda hoje causa surpresa entre os estudiosos da linguagem a presença dos capítulos dedicados ao tema ${ }^{2}$ na edição apresentada por Bally e Sechehaye em 1916. O segundo viés apontado no estudo do fônico em Saussure está ligado à noção de significante - ou imagem acústica - desenvolvida pelo linguista genebrino. Mesmo que inseparável da porção de significado para que se conceba a unidade signo, o estudo do significante ocupa uma parte importante ${ }^{3}$ das aulas de Saussure.

2. "A Fonologia", capítulo VII da Introdução e "As espécies fonológicas" e "O fonema na cadeia falada", capítulos I e II do Apêndice "Princípios de Fonologia", do clássico livro Curso de Linguística Geral (1974). 
No percurso desse texto, dando ênfase ao aspecto fônico da língua, discutirei o estatuto da materialidade sonora com objetivo de revisitar as noções de fonema, fonética e fonologia a partir do legado do mestre genebrino. Do corpus saussuriano tomarei como ponto de partida o Curso de Linguística Geral (1974), mas apontarei também comparativamente passagens dos Escritos de Linguística Geral (2004) e do manuscrito Phonétique (1995). A escolha dessas fontes é determinada por duas variáveis: a primeira diz respeito ao fato de o Curso de Linguística Geral e os Escritos de Linguística Geral ${ }^{4}$ serem as obras de maior circulação e divulgação do pensamento desse autor. O segundo motivo diz respeito à especificidade de uma fonte que, embora tenha pouca circulação, aborde especificamente o tema do aspecto fônico da língua.

Vale ainda destacar que, para o presente trabalho, iniciarei sublinhando importantes constatações da reflexão do linguista belga Semir Badir (2012) acerca das noções de concreto e abstrato na fonologia e na fonética saussurianas. Na leitura que faço do legado do genebrino, a circunscrição da unidade de análise linguística não só depende da dupla existência concreta-abstrata do signo linguístico como também determina epistemologicamente a abordagem sincrônica do sistema. Ou seja, partir das noções de concreto e de abstrato na abordagem do aspecto fônico da língua é decisivo para operar metodologicamente em uma visão saussuriana do tema.

\section{Aspectos concretos e abstratos do fônico}

Badir (2012:13), ao investigar o estatuto dos termos concreto e abstrato na obra saussuriana, busca as configurações semânticas e sintáticas nas quais esses termos são (ou não) utilizados. Já em um

4. Editada por Bouquet e Engler, a publicação Escritos de Linguística Geral reúne textos encontrados em 1996 e antigos documentos (Edição Engler, 1968-1974 e Acervo da Biblioteca Pública e Universitária de Genebra). Do ponto de vista filológico, cabe destacar a fundamental importância que tem, para o pesquisador das fontes manuscritas saussurianas, a pormenorizada edição desse mesmo manuscrito realizada por René Amacker, em 2011, com o título de Science du langage: de la double essence du langage (Saussure 2011). No presente texto, no entanto, optei por trabalhar com a versão de Bouquet e Engler, em função de sua larga divulgação no Brasil, através da tradução de Carlos Augusto Salum e Ana Lucia Franco (Saussure 2004). 
primeiro esclarecimento, o linguista anuncia que concreto, em Saussure, não é sinônimo de "objeto da linguística". Feita essa ressalva, o autor mostrará, através de quatro diferentes vias ${ }^{5}$, que concreto e abstrato em fonética e em fonologia tomam caminhos diferentes.

Concordamos inteiramente com o autor ao afirmar que a pista fônica (concreta) não garante per se a abstração. De acordo com esse pesquisador, embora os estudos linguísticos tendam a ter como ponto de partida o dado concreto, não há um objeto primeiro "mais tangível" do que o objeto abstrato. Essa observação terá efeito evidente na forma com que, alinhada com esse autor, proponho uma abordagem saussuriana do aspecto fônico da língua: os sons que a fonologia estuda ainda não foram realizados; são ideias de sons tomados como valores absolutos (Badir 2012:19).

Poder-se-ia perguntar por que o impasse entre concretude e abstração é ponto de partida para o estudo do fônico. O próprio texto do Curso de Linguística Geral' anuncia: "Esta [a imagem acústica] não é o som material, coisa puramente física, mas a impressão (empreinte) psíquica desse som, a representação que dele nos dá o testemunho de nossos sentidos" (Saussure 1974:80).

Tudo indica que definir a unidade de análise da qual o linguista se ocupa parece ter sido uma decisão importante para o mestre genebrino. Encontra-se também ecos desse impasse conferido à abordagem do aspecto sonoro da língua em Saussure nos Escritos de Linguística Geral ${ }^{7}$. Em determinada passagem anotada como "Préfácio", Saussure alerta: "É errado (e impraticável) opor a forma e o sentido. O que é certo, em troca, é opor a figura vocal, de um lado, e a forma-sentido de outro". (Saussure 2004:21). Ou seja, pode-se perceber que Saussure parte do princípio de que o aspecto fônico da língua é, ao mesmo tempo, a

5. Os quatros caminhos apontados por Badir são: 1. Do abstrato ao concreto em fonética; 2. Do concreto ao abstrato em fonética; 3 . Do concreto ao abstrato em fonologia; 4. Do abstrato ao concreto em fonologia.

6. Neste trabalho, utilizarei alternadamente o nome da obra por extenso e a conhecida sigla $C L G$.

7. Neste trabalho, utilizarei alternadamente o nome da obra por extenso e a sigla $E L G$.

8. Conforme Bouquet e Engler (Saussure 2004:15), editores dos ELG, esse registro de "Prefácio" é uma anotação do próprio Saussure, quiçá para um livro sobre linguística geral. 
prova da realização concreta da mesma e a necessária abstração que ela (a língua) impõe.

É também nessa fonte manuscrita, editada por Bouquet e Engler, que, algumas páginas mais adiante, o leitor depara-se com a inquietante discussão de Saussure acerca do estatuto dos aspectos concretos (sejam eles acústicos ou articulatórios) e dos aspectos abstratos na reflexão sobre o funcionamento do sistema de sons da língua:

Não se pode definir o que é uma forma com a ajuda da figura vocal que ela representa - e também não com a ajuda do sentido que contém essa figura vocal. Fica-se obrigado a colocar, como fato primordial, o fato GERAL, COMPLEXO e composto de DOIS FATOS NEGATIVOS: da diferença geral das figuras vocais associada à diferença geral dos sentidos que se pode atribuir a elas. (Saussure 2004:31).

Eis, portanto, um alerta: tomar a porção significante do signo linguístico como pura concretude é absolutamente equivocado. Ao contrário, lidar com a forma-sentido é supor na materialidade fônica o estatuto da representação. Tudo indica que, antes da virada epistemológica produzida pela inovação saussuriana, ficou-se por muito tempo atado ao fato de que há, na língua, a divisão radical entre um lado físico e um lado psíquico. Em suas aulas na Universidade de Genebra, o mestre já alertava que o "erro foi acreditar que o lado psíquico é a ideia enquanto o lado físico é o som, a forma, a palavra" (Saussure 2004:60). Isso porque o elemento sonoro concreto não aparece nunca sozinho, isolado. Ele está preso na cadeia sonora que constitui a fala. Ou seja, dela ele faz parte e é dependente. É, portanto, em sua existência dupla que o elemento sonoro concreto produz relação de diferença e oposição em relação a todos os outros elementos. Ou seja, potência diferenciadora no sistema é atualizada pela capacidade abstrata do som da língua produzir contraste no sistema.

É surpreendente acompanhar o raciocínio do linguista genebrino ao apontar a necessidade de considerar essa potência representacional da unidade de análise da língua, via reconhecimento da categoria "entidade" como abstração:

É imediatamente visível que as entidades da ordem vocal ou consistem na identidade que acabamos de considerar, por conseguinte num fato perfeitamente abstrato, ou em nada consistem e não estão em parte alguma. 
Os fatos, tomados em si mesmos, que por si sós certamente são concretos, se vêem condenados a não significar absolutamente nada, a não ser por sua identidade ou não-identidade. O fato, por exemplo, de aka ser pronunciada por uma pessoa, num certo lugar e num certo momento, ou o fato de mil pessoas, em mil lugares e em mil momentos, emitirem a sucessão de sons $a k a$, é, absolutamente, o único fato dado: mas não é menos verdade que só o fato ABSTRATO, a identidade acústica desses aka, forma sozinho a entidade acústica aka: e que não há um objeto primeiro a ser procurado, mais tangível do que esse primeiro objeto abstrato. (Saussure 2004:33)

No entanto, no próprio Curso de Linguística Geral, encontram-se flutuações quanto à forma de abordar o estudo dos aspectos fônicos da língua. Nos recortes abaixo, duas ocorrências representativas dessas posições discrepantes podem se evidenciadas:

- De um lado, percebe-se o destaque do aspecto concreto do signo:

“O significante, sendo de natureza auditiva,..." (Saussure 1974:84); e

- Por outro lado, observa-se a abordagem abstrata do signo:

"O essencial da língua é estranho ao caráter fônico do signo linguístico" (Saussure 1974: 14).

Essas oscilações quanto ao aspecto material do signo linguístico presentes no $C L G$, merecem ser tratadas em conjunto. Isso porque o amparo no fônico não deve ser um fim em si mesmo, mas uma sustentação na qual se ancora a representação. Não será na realização fônica em si que a significação e o valor linguísticos se constituirão, mas através do fato de elas serem materialidades desde as quais evidencia-se um jogo de diferenças e oposições.

Contarastando com os $E L G$, encontra-se a afirmação de que a língua precisa de suporte fônico (os adjetivos, advérbios etc que estão na língua enquanto tal), mas que isso não está garantido antecipadamente através da realização vocal (Saussure 2004: 106). Ou seja, pode-se daí depreender que a fala necessita da realização vocal, embora o valor linguístico não dependa dessa forma vocal propriamente dita, mas apenas da diferença entre as formas. Afinal, nunca se sabe de antemão o valor que cada elemento vai ganhar no ato de fala (um adjetivo por virar substantivo, um alongamento vocálico pode gerar efeito irônico, por exemplo). 
Não parece detalhe lembrar ainda que, no "Apêndice de Fonologia" do $C L G$, Saussure anuncia a dependência recíproca dos fonemas (Saussure 1974:62) e destaca o efeito produzido pelos fonemas ao ouvido (Saussure 1974:63). Nesse contexto, o mestre aponta: "Pela primeira vez, saímos da abstração; pela primeira vez, aparecem elementos concretos, indecomponíveis, ocupando um lugar na cadeia falada." (Saussure 1974:66). E, em seguida, encontra-se: "Foi um grande erro da Fonologia considerar como unidades reais essas abstrações, sem examinar mais de perto a definição de unidade" (Saussure 1974:66).

Começa a ficar claro qual o empreendimento metodológico em questão. Saussure fornece duas importantes pistas: por um lado, a necessidade de o linguista circunscrever a noção de unidade; por outro lado, a importância de o pesquisador atentar para o efeito acústico produzido pela diferença entre as unidades no seio da cadeia falada. É exatamente isso que se encontra no legado do genebrino, conforme documentado no $C L G$ : "No ato fonatório que vamos analisar, levamos em conta apenas os elementos diferenciais, destacados para o ouvido e capazes de servir para uma delimitação das unidades acústicas na cadeia falada" (Saussure 1974:67).

Será sob efeito dessa observação que cabe sublinhar a noção de unidade, tão cara a Saussure. A consideração acerca da relação entre concreto e abstrato, quando se investe em um estudo dos aspectos fônicos da língua, merece, portanto, um detalhamento. Esse detalhamento, conforme apontado acima, pode (e deve) ser realizado a partir das pistas deixadas pelo próprio linguista genebrino em suas produções, tanto as mais como as menos conhecidas ${ }^{9}$.

É no corpus escolhido para esse estudo que empreenderemos um percurso em busca da noção de unidade e campo, a fim de espreitarmos a construção de uma forma de compreender o funcionamento fônico das línguas. Circunscrita a unidade, poderemos tangenciar leituras

9. Cabe lembrar que para o presente estudo foram considerados apenas três documentos de Ferdinand de Saussure. O vasto legado do linguista genebrino compreende um tesouro ainda pouco explorado composto por fontes manuscritas (publicadas e não-publicadas), correspondências, esboços de aulas, edições críticas do $C L G$, cadernos dos alunos que frequentaram seus cursos, inúmeros cadernos contendo análise de anagramas, vários cadernos de análise de lendas germânicas, estudos sobre o sânscrito, sobre o indoeuropeu e sobre o lituano, entre outros tantos documentos. 
possíveis da abordagem acerca das noções de fonética e de fonologia no legado do mestre.

\section{A unidade e o campo: o fonema, a fonética e a fonologia}

Definir unidades faz parte do empreendimento do linguista ao analisar o seu objeto. Vemos que, ao mesmo tempo em que se preocupava em definir as unidades com as quais trabalha o linguista, Saussure alertava para o fato de que elas jamais poderiam ser dadas de antemão. É sempre no seio do sistema que a delimitação e a função de um elemento podem ser concebidas. Eis como isso aparece nos ELG:

\begin{abstract}
A presença de um som, numa língua, é o que se pode imaginar de mais irredutível como elemento de sua estrutura. É fácil mostrar que a presença desse som determinado só tem valor por oposição com outros sons presentes; e é essa primeira aplicação rudimentar, mas já incontestável do princípio das OPOSIÇÕES, ou dos VALORES RECÍPROCOS, ou das QUANTIDADES NEGATIVAS e RELATIVAS que criam um estado de língua. (Saussure 2004:27)
\end{abstract}

Essa passagem dos $E L G$ não deveria surpreender, pois ela confirma algo já presente no $C L G$, a clássica afirmação que "na língua só existem diferenças" (Saussure 1974:139). E, de forma mais clara ainda, na mesma obra, a indicação que "os fonemas são, antes de tudo, entidades opositivas, relativas e negativas" (Saussure 1974:138). Sem dúvida, trata-se de uma consideração relevante acerca do sistema fônico como organizador da lógica pautada pela teoria do valor, o que, como se sabe, produziu significativos efeitos sobre os trabalhos de dois expoentes do Círculo Linguístico de Praga, mais especificamente Jakobson e Troubetzkoy.

Resumindo: a partir do legado saussuriano, entende-se que a garantia de existência de um signo linguístico é evidenciada pelo fato de que ele produza diferença e oposição dentro do sistema. No entanto, para que se possa proporcionar efeitos contrastivos, precisamos de uma materialidade que carregue e sustente essa(s) diferença(s). Se um signo é o que os outros não são, é necessário buscar uma pista na realidade concreta desse signo para que se possa identificá-lo como pertencente 
a uma dada língua e opô-lo a todos os demais signos dessa língua. É nesse contexto que se buscará contribuir para a dicussão das noções de fonema, fonética e fonologia, no âmbito das pesquisas saussurianas contemporâneas.

\subsection{O fonema}

A definição de fonema nas fontes nesse trabalho elencadas não é unívoca. Percebe-se, nos diferentes materiais consultados, apontamentos que mostram momentos distintos na construção da concepção dessa unidade linguística para Saussure. A seguir, serão destacados alguns aspectos dessa diversidade.

No $C L G$, particularmente no apêndice "Princípios de Fonologia", dois aspectos chamam a atenção no que diz respeito à noção de fonema. Em primeiro lugar, merece destaque a preocupação do mestre genebrino em relação ao aspecto perceptivo. Expressões como caráter distintivo, ouvido(a) e acústico(a) são recorrentes, ao apresentar a definição de fonema. Saussure destaca que o ato articulatório está absolutamente apoiado na impressão acústica produzida no ouvido dos falantes, criando assim uma interdependência:

O fonema é a soma das impressões acústicas e dos movimentos articulatórios da unidade ouvida e da unidade falada, das quais uma condiciona a outra; portanto, trata-se já de uma unidade complexa, que tem um pé em cada cadeia. (Saussure 1974:51)

Em segundo lugar, é importante destacar que a análise das unidades fonológicas, no $C L G$, é apresentada a partir da perspectiva da "cadeia de fala", conforme já foi comentado acima. O linguista fala da importância dos "elos" da cadeia (Saussure 1974:51), destacando a relação de "dependência interna" (Saussure 1974:62) entre esses elementos. Esse apontamento parece fundamental, pois repercute na proposta saussuriana de uma "fonologia combinatória" (Saussure 1974:64), conforme será enfatizado logo adiante.

Nos $E L G$, Saussure registra que, para os fonologistas de sua época, havia duas perspectivas de fonema: 
Uma (a respeito da qual eles evitam se explicar) em que o fonema vive, à parte, uma vida sem dúvida difícil de definir e captar, mas dada como de tal modo evidente que não precisa ser explicada nem justificada. Depois, a outra, em que o fonema até aí solitário e flutuando no espaço, entra em combinação com os outros. (Saussure 2004:125)

Para o mestre genebrino, essa segunda forma, quando era (raramente) levada em consideração, era vista como secundária. Frente a essa tendência de se considerar o fonema isoladamente, Saussure se contrapõe explicitamente:

Contra essa concepção, o protesto que levanto consiste simplesmente nisto: é preciso definir a unidade fonatória e, definida essa unidade, ver-se-á a ausência de qualquer diferença entre a unidade no encadeamento. Não mais se imaginará que, por um lado, os fonemas planam no céu e que, por outro lado, caem às vezes na cadeia falada. $\mathrm{O}$ maior erro dos fonologistas que eu ataco não é ter imaginado que os fonemas, "ao entrar no encadeamento", estão sujeitos a um regime especial, ainda que essa ideia seja extraordinária, mas ter aceito a ideia de que existiria outro avatar qualquer dos fonemas além do que se vê no encadeamento e ter propagado a ideia de que $B$ ou $Z$ ou L representam unidades, ou até mesmo "unidades imediatamente dadas", sem nenhuma tentativa de mostrar a que corresponde uma tal afirmação. (Saussure 2004:126)

É a partir dessa empolgada e inquieta manifestação que se deve ler outra importante passagem dos $E L G$ :

Presença de um fonema = sua oposição com os outros fonemas presentes, ou seu valor com relação a eles.

Correlação de dois sons (sem "significação") = sua oposição mútua, seu valor, um com relação ao outro.

Correlação de dois fonemas com correlação de "significações" diferentes = sempre simplesmente seu valor recíproco. É aqui que se começa a entrever a identidade de significação e do valor.

Depois disso: o que fizemos? Nós partimos do elemento fonológico como de uma unidade morfológica que adquire, sucessivamente, diferentes funções, mas em nenhum momento, um som, ele mesmo, é dado como unidade morfológica. (Saussure 2004:28)

Mais do que pensar uma proposta didática para a leitura da noção de fonema em Saussure, o que se pode reconhecer nas anotações do 
mestre é uma preocupação em conceber unidades passíveis de análise linguística que não incorram no erro/risco de serem concebidas desde seu aspecto puramente fônico. Mais uma vez, merece ser sublinhado que a noção de fonema em Saussure passa necessariamente pela consideração dos sons da língua em contexto de relação, ou seja, respaldados pelo valor que as relações entre os sons de uma dada língua estabelem entre si.

É isso que confirma a outra fonte consultada, o manuscrito Phonétique. Nesse importante documento depositado na biblioteca de Harvard, além da afirmação de que o fonema condensa um conjunto simultâneo de características distintivas (Saussure 1995:26) e de que ele repousa em uma cadeia combinatória (Saussure 1995:28), encontra-se um significativo registro do jovem ${ }^{10}$ Ferdinand de Saussure:

PHONÈME = phénomène phonétique opposé à SILENCE

PHONÈMES individuels opposés entre eux

PHONÈME représentant portion de temps par opposition à ESPÈCE PHONÉTIQUE

PHONÈME par opposition à AUDITION (par opposition à synchronie physiologique)

PHONÈME par opposition à CHAÎNON (Saussure 1995:81) $)^{11}$

Deve-se dar destaque ao que aponta Marchese (1995) ${ }^{12}$, ao considerar a construção da noção de fonema em Saussure a partir da leitura do manuscrito Phonétique. Para a linguista italiana (Marchese 1995: XXIII), o dualismo acústico e articulatório do fonema deve ser considerado a partir da ideia de unidade proposta pelo próprio mestre em seus manuscritos. Segundo a autora, essa é inclusive uma pista que se

10. Segundo apontam Marchese (2009:X) e D’Ottavi (2014:99), os manuscritos Phonétique datam de 1883-1884.

11. FONEMA= fenômeno fonético oposto ao SILÊNCIO

FONEMAS individuais opostos entre si

FONEMA como porção representante de tempo por oposição à ESPÉCIE FONÉTICA FONEMA por oposição à AUDIÇÃO (por oposição à sincronia fisiológica) FONEMA por oposição a ENCADEAMENTO (tradução nossa).

12. A linguista italiana Maria Pia Marchese é a atual curadora do Manuscrito Phonétique, documento composto por um grupo heterogêneo de fontes manuscritas de Ferdinand de Saussure, que pertence à Houghton Library of Harvard University. 
tem acerca da decisão metodológica de Saussure, ao propor o signo como unidade de análise.

Importante destacar que, nesse manuscrito, Saussure aponta claramente que a noção de fonema pressupõe que um efeito seja produzido. Essa afirmação vem acompanhada da ressalva feita em relação ao ato de fonação. Ou seja, o mestre não descarta a necessidade de se considerar os fatores de produção ("mettant à part l'emission, toujours nécessaire,...”, Saussure 1995:76). No entanto, é surpreendente perceber que é na orelha do falante que ele ancora sua definição de fonema ("phonème suppose que l'effet est produit", Saussure 1995:82).

O lugar de destaque do ouvinte e da orelha no legado saussuriano foi já brilhantemente destacado por Herman Parret (2002, 2014). O linguista e semioticista belga (Parret 2002:54) aponta que Saussure subordina o fenômeno fonético ao fenômeno acústico. Vê-se que a noção de unidade é questionada pelo autor, ao levantar uma indagação acerca da percepção obtida através da orelha ("A impressão acústica é definível?" (Parret 2002:56). É por esse motivo, no entender de Parret, que metodologicamente foi necessário ao mestre genebrino suspender as qualidades naturalizantes da língua (mecânica, fisiológica, articulatória) para considerar o ato fônico como condicionado à impressão acústica.

Assim, tudo indica que uma saída possível para os impasses dualistas (concreto/abstrato, articulatório/acústico) seja pensar que a injunção concreto-abstrato proposta para o fonema é absolutamente contingente quando refere-se à fala. Aliás, contingente e necessária, parafraseando Émile Benveniste. Diferentemente, quando se está no terreno da língua, é sempre de abstração que se trata. Afinal, para a língua, os fonemas, enquanto entidades diferenciais e formais, são apenas abstrações ${ }^{13}$.

Isso indica que, do ponto de vista da língua, para que se reconheça a unidade fonema, é suficiente que se conte com elementos que carreguem registros abstratos de diferença. Já desde o ponto de vista

13. Tullio de Mauro, na nota 111 de sua edição crítica do $C L G$, anuncia sua contrariedade em relação a essa dupla interpretação do conceito de fonema na obra saussuriana. 
da fala, para que se reconheça o fonema como unidade, precisaremos contar com o efeito perceptivo que ele produz. Ou seja, para que um som seja alçado à instância de signo, ou seja, de fonema, é necessário que ele seja reconhecido como passível de evocar simultaneamente, através de sua materialidade fônica, impressão acústica e registro de diferença(s). Isso confirma sua dupla natureza concreta e abstrata.

\subsection{A fonética e a fonologia}

Após ter-se discutido o duplo caráter (concreto e abstrato) da abordagem saussuriana do aspecto fônico da língua e detido-se na noção de unidade destacada pelo mestre, cabe, a seguir, voltar o olhar para a forma como esse campo de estudos foi constituído. O que se pode chamar de fonética e de fonologia no legado do mestre genebrino? Todo cuidado será pouco para que não se incorra no risco de propor apressadas simplificações.

Em algumas passagens do Curso de Linguística Geral é possível e pertinente interpretar o uso do termo fonologia como "fonética fisiológica", conforme se pode acompanhar a seguir:

A fisiologia dos sons (em alemão Lauthphysiologie ou Sprachphysiologie) é frequentemente chamada de "Fonética" (em alemão Phonetik, inglês phonetics, francês phonétique). Esse termo nos parece impróprio; substituímolo por Fonologia. Pois Fonética designou a princípio, e deve continuar a designar, o estudo das evoluções dos sons; não se deveriam confundir no mesmo título dois estudos absolutamente distintos. A Fonética é uma ciência histórica; analisa acontecimentos, transformações e se move no tempo.

A Fonologia se coloca fora do tempo, já que o mecanismo da articulação permanece sempre igual a si mesmo. (Saussure 1974:43)

Não parece complicado entender, a partir da passagem acima, que o termo fonética para Saussure está relacionado ao estudo da evolução histórica dos sons das línguas. Quanto a isso não parece que caiba qualquer ajuste. No entanto, é comum se fazer relação direta entre a noção saussuriana de fonologia e o estudo que hoje conhecemos como fonética. A leitura detalhada das páginas do $C L G$ não confirmam essa interpretação. Cabe uma visita ao $C L G$, precisamente em uma passagem elucidativa: 
Por aí se vê a importância que a fonologia dos grupos deve ter para a Linguística Geral. Enquanto os fonólogos se limitam geralmente a dar regras para articular todos os sons, elementos variáveis e acidentais das línguas, essa Fonologia combinatória circunscreve as possibilidades e fixa as relações constantes dos fonemas interdependentes. (Saussure 1974:64)

Vê-se, no recorte acima, que, ao falar de uma fonologia combinatória, Saussure anuncia um estudo do sons da língua dependente de relações. Ou seja, trata-se de uma abordagem não isolada dos elementos. Pelo contrário, a menção às relações entre os elementos e à sua interdependência demonstra o caráter sistêmico de sua abordagem.

Em uma investigação igualmente meticulosa, nos $E L G$ se pode acompanhar os impasses de Saussure em relação à nomeação do campo dos estudos do aspecto fônico da língua:

FONOLOGIA (ou estudo da fonação). - Estudo que receba o nome que for, é absolutamente independente e distinto, não apenas da fonética das diferentes línguas mas, em geral, da linguística. (Saussure 2004:75)

Se, como se pode ver acima, a fonética parte do concreto para chegar ao abstrato, sabe-se que a fonologia realiza o caminho inverso. A fonologia parte do abstrato, mesmo que precise em algum momento contar com a sustentação em aspectos concretos dos sons da língua. Por esse motivo se pode dizer que o estatuto do fônico em Saussure é simultaneamente concreto e abstrato: é concreto porque depende de uma materialidade e é abstrato porque depende do valor. Nesse sentido, concordamos totalmente com Badir (2012:22), ao afirmar que definir um conceito de fonema a partir do legado saussuriano é ir em direção à coincidência entre o movimento articulatório e a impressão acústica.

É também nos ELG que é possível encontrar uma concepção, pode-se dizer bastante visionária, de fato fonológico. Percebe-se, na passagem a seguir, o quanto a implicação entre concreto e abstrato repercute na definição do objeto da linguística e, consequentemente no fazer do linguista:

Assim é na fonologia, assim como na linguística, e em qualquer disciplina que tenha a infelicidade de correr sobre duas ordens de fatos separadas, onde só a correlação já criou o fato a ser considerado. Assim como afirmaremos 
adiante, é grandemente ilusório supor que se pode discernir, em linguística, uma primeira ordem, SONS, e uma segunda ordem, SIGNIFICAÇÕES, pela simples razão de que o fato linguístico é fundamentalmente incapaz de se compor de uma só dessas coisas e nunca pede, para existir, uma SUBSTÂNCIA, NEM DUAS substâncias, assim como constatamos que nem o fato mecânico nem o fato acústico, situados cada um em sua esfera, representam o fato fonológico, de que é preciso partir e para o qual é preciso retornar; mas que é a forma contínua de sua correlação que chamamos de fato fonológico. (Saussure 2004:204)

Frente a essa constatação do fato fonológico, ou seja, da consideração concomitante do som e da significação, ou do efeito acústico e do efeito de sentido que um signo é capaz de produzir, o mestre desabafa:

Nós não temos nenhum gosto pela fonologia e rogamos ao leitor que acredite que a espécie de sistema que, para nosso uso pessoal, empregamos há quinze anos, tem, como única pretensão, substituir os ensinamentos dos fonologistas até que os fonologistas queiram, eles mesmos, se ocupar da silabação e ensiná-la a nós. Não pode caber ao linguista reparar as omissões da fonologia. Essas omissões são, infelizmente, tais que não resta outra alternativa a este último além de construir, assim, sua própria fonologia. (Saussure 2004:209)

Nesse sentido, acompanhando o raciocínio saussuriano, encontrase aquilo que parece ser o embrião de seus estudos sobre o aspecto fônico da língua: "Seria ingenuidade querer edificar uma fonologia sobre a suposição de que o fato fonológico é a causa da qual as figuras acústicas são o efeito" (Saussure 2004:211).

É por esse motivo que, a partir dos $E L G$, pode-se pensar nos estudos do fônico na língua como uma "teoria dos efeitos" (Saussure 2004:213). Trata-se de considerar que o som provoca a ideia, ou inversa e reciprocamente. Conforme alerta Saussure, se a fisiologia da fala é regida por leis físicas, no estudo linguístico dos sons da língua o que deve valer é a consideração de uma relação arbitrária na origem. Por esse motivo, parece consequente reconhecer em seus registros a proposta de uma fonologia combinatória. Uma fonologia combinatória que pressupõe leis que presidem a disposição dos fonemas (Saussure 2004:214). Essa fonologia combinatória é consequência da necessidade de uma 
abordagem que busque "uma explicação clara sobre a nova situação do fonema" (Saussure 2004:125). Para o genebrino, a constatação da diferença de abordagem isolada ou relacional dos fonemas

[...] incita apenas observações sobre o fato da combinação e sobre o fato de que, na combinação, não se pode esperar que seja tudo semelhante ao que tinha sido dito sobre o fonema "isolado". A primeira maneira de considerar o fonema ocupa a primeira parte dos tratados. A segunda, quando não está ausente, constitui um capítulo final, [...].”(Saussure 2004:125-126)

Pela quantidade de material produzido ${ }^{14}$ por Ferdinand de Saussure sobre o aspecto fônico da língua, cabe dizer que há claros indícios de uma proposta de um campo de estudos do fônico a partir da noção de fonologia combinatória.

No manuscrito Phonétique há passagens em que Saussure propõe claramente o estudo do fonema na "chaine phonetique" (Saussure 1995:28). Sem descartar a importância do estudo acerca da produção fisiológica dos sons "des termes de classification physiologique des sons", (Saussure 1995:28-29), Saussure sublinha a necessidade de se implementar um estudo do som como elemento de uma cadeia. Nas folhas do manuscrito de Harvard, percebe-se um inquieto linguista indagando: "Dans quelle mesure le fait de la continuité d'articulation du phonème joue-t-il un rôle dans la chaine phonétique?" (Saussure 1995:19).

Não faltam exemplos de termos espalhados pelo manuscrito Phonétique que demonstram a preocupação de Saussure com uma abordagem sistêmica dos sons da língua. Expressões como "le rapport" (1995:21), "le système" (1995:23), "valeur" (1995:87), "rôle" (1995:79), "effets acoustiques" (1995:9), "la châine phonétique" (1995:19), "caractère distinctif” (1995:26), “combinaisons possibles” (1995:27) são abundan-

14. Além das fontes consultadas para o presente estudo ( $C L G, E L G$ e Phonétique), é importante destacar que as questões acerca do lugar do fônico no conjunto de reflexões saussurianas se apresentam em vários documentos: no manuscrito das Soantes (2002), no manuscrito Notes sur l'accentuation lituanienne (2003), nos estudos sobre os Anagramas (1974) e Mémoire sur le système primitif des voyelles dans les langues indoeuropéennes (1984). 
tes ${ }^{15}$. Esses indícios apontam para a presença significativa do aspecto fônico da língua na reflexão linguística de Ferdinand de Saussure, conforme destacamos reiteradamente nesse trabalho.

\section{Encaminhamentos finais}

O percurso realizado através do presente estudo tratou de procurar rastros deixados por Ferdinand de Saussure no que diz respeito ao aspecto fônico da língua. Para tanto, a leitura feita do clássico livro Curso de Linguística Geral, da reunião de manuscritos do Escritos de Linguística Geral e do manuscrito Phonétique foi fundamental. Com ela, buscou-se lançar luzes sobre um tema geralmente minimizado na abordagem da obra saussuriana. Trata-se de uma interpretação das ideias de Saussure a partir da aposta na consideração dos sons das línguas.

Além disso, acompanha a reflexão realizada no decorrer deste trabalho a ideia de uma releitura do lugar do fônico no legado saussuriano. Acreditamos que, a partir da pesquisa aqui apresentada, é possível e pertinente pensar na unidade fonema e no campo da fonologia ancorados nos princípios saussurianos de sistema e de valor. Assim, vislumbra-se uma perspectiva de estudos de uma fonologia combinatória, para utilizar precisamente o termo presente no CLG.

Recebido em: 27/12/2016

Aprovado em: 17/05/2017

E-mail: luizamilanos@gmail.com

\section{Referências}

BADIR, Semir. 2012. Le concret et l'abstrait dans la phonologie et dans la phonetique de Saussure. Cahiers Ferdinand de Saussure, 65:13-23.

D’OtтAVI, Giuseppe. 2014. Nine easy pieces: les manuscrits de Ferdinand de Saussure à Harvard. In: ChePIGA, Valentina; Sofia, Stanislau (eds.). Archives et manuscrits de linguists. Paris: Academia-L'Harmattan.

15. Embora não tenhamos realizado (ainda) um estudo exaustivo das ocorrências, os termos que aqui elencamos estão fartamente presentes ao longo do manuscrito. Por esse motivo, optamos, por ora, indicar, de forma ilustrativa, apenas uma ocorrência de cada um deles. 
MARCHESE, Maria Pia. 1995. Les manuscrits saussuriens sur la phonétique, du Mémoire au Cours de linguistique Générale. Cahiers Ferdinand de Saussure, 62:47-61.

. 1995. Introduzione. In: SAussure, Ferdinand de. Phonétique: Il manoscritto di Harvard. Houghton Library, edizione a cura de Maria Pia Marchese, Università degli studi di Firenze. Padoue: Unipress.

Milano, Luiza. 2016. O fônico em Saussure: um apêndice do Curso de linguística geral? In: FARACo, Carlos Alberto (ed.). O efeito Saussure. São Paulo: Parábola Editorial.

. 2015. Fonético e fonológico em Saussure : o lugar do fônico no Curso de linguística geral. Eutomia, 16 (1): 245-258.

PARRet, Herman. 2002. La voix et son temps. Bruxelas: De Boeck \& Larcier.

.2014. Le son et l'oreille: six essais sur les manuscritos saussureins de Harvard. Paris: Lambert-Lucas.

Saussure, Ferdinand de. 1974. Curso de Linguística Geral. São Paulo: Cultrix.

. 1972. Cours de Linguistique Générale. Édition critique préparée par Tullio de Mauro. Paris: Payot.

.2004. Escritos de Linguística Geral. Organizados e editados por Simon Bouquet e Rudolf Engler. São Paulo: Cultrix.

. 1995. Phonétique: Il manoscritto di Harvard. Houghton Library, edizione a cura de Maria Pia Marchese, Università degli studi di Firenze. Padoue: Unipress.

. 2002. Théorie des sonantes: Il manuscritto di Geneva. Edizione a cura de Maria Pia Marchese, Università degli studi di Firenze. Padoue: Unipress.

. 2003. Notes sur l'accentuation lituanienne. In: BouQuet, S. (org.).

Cahiers de l'Herne. Saussure. Paris: Éditions de l'Herne. 2009. Mémoire sur le système primitif des voyelles dans les langues indo-européenne. New York: Cambridge University Press.

StAROBInSKI, Jean. 1974. As palavras sob as palavras: os anagramas de Ferdinand de Saussure. São Paulo: Editora Perspectiva.

Surreaux, Luiza Milano. 2013. O rastro do som em Saussure. Nonada, 20 (1):285-295. 